ISSN 0001-6002/2002/44/3/103-104

A cta M édica Costarricense, $\bigcirc 2002$

Colegio de M édicos y Cirujanos

\title{
Editoriales
}

\section{Colecistectomía laparoscópica}

La cirugía de la vesícula y de las vías biliares ha seguido un largo camino. De acuerdo con la literatura norteamericana, B obbs en Indiana en 1867 realizó la primera colecistectomía. Como el término implica se abre la vesícula, se retiran los cálculos y se coloca dentro del órgano un drenaje, el que se exterioriza. Esa intervención se popularizó para pacientes con colecistitis aguda, empiema o hidrops vesicular, es decir, en condiciones agudas del tracto biliar, en las cuales aún conociendo la anatomía no se había pensado en la remoción completa del órgano 0 ésta no era posible en las condiciones de anestesia de la época.

En 1882 Langenbuch realizó en Berlín la primera colecistectomía clásica, recomendándola en casos de colecistitis crónica, gangrena vesicular y también para aquellos individuos cuyo proceso original se había tratado primero con una colecistostomía ${ }^{1}$. Este autor reconoció "que era necesario extirpar la vesícula, no porque contenía los cálcul os sino porque los hacía" ${ }^{2}$. Rápidamente se empezaron a acumular grandes series de colecistectomías en Europa y A mérica y ya para principios del siglo $X X$ se reportaba una mortalidad quirúrgica de $3.6 \%{ }^{1}$.

Paral elamente se fueron agregando otros procedimientos a la cirugía del árbol biliar, como la coledocostomía, la hepatostomía y así por varias décadas la enfermedad litiásica fue tratada mediante la laparotomía extirpando la vesícula y "explorando la vía biliar", para remover los cálculos y permeabilizar el flujo hacia el duodeno. La única contraindicación para esta intervención era una condición clínica incompatible con la administración de anestesia general. Con el paso del tiempo factores como destreza quirúrgica, mejores técnicas de anestesia, antibióticos, etc., se conjugaron y la mortalidad operatoria de esta intervención en los años 90 ya había bajado a alrededor del $1 \%(0.6 \text { al } 1.7 \%)^{3.4}$.

Sin embargo, durante el último cuarto del siglo pasado se propusieron métodos alternativos de tratamiento de la litiasis vesicular: técnicas de litotripsia con ondas de choque extracorpóreas, ingestión de disolventes de cálculos, inyecciones percutáneas intravesiculares de disolventes, o bien procedimientos quirúrgicos con incisiones mucho más pequeñas utilizando instrumentos un tanto diferentes, magnificación y lámparas frontales siempre con la idea de minimizar la intervención, el dolor y por lo tanto las complicaciones ?

Por otro lado, también durante los primeros años del siglo pasado, otros investigadores utilizando cistoscopios e instrumentos modificados se aventuraron a hacer laparoscopías ayudados con la producción de pneumoperitoneo (llamadas entonces celioscopías 0 peritoneoscopías) y también toracoscopías diagnósticas y terapéuticas. En 1918 se describió una aguja especial para la producción del pneumoperitoneo, pero en 1938 Veress reportó una más segura con un resorte interno, la cual es usada aún en nuestros días. Posteriormente otro investigador propuso la creación del pneumoperitoneo inyectando el gas por un trócar umbilical introducido bajo visión directa, y no por la aguja que era y es aún hoy, introducida a ciegas. Esta técnica es preferida por muchos grupos quirúrgicos.

La verdadera explosión en este campo ocurrió de los años 50 a los 80, en que nacieron las cámaras de alta resolución (solid state), con las cuales se podía trabajar bajo visión directa, avance que fue luego superado con la introducción del chip, que permitió transmitir a un monitor una imagen nítida y a colores ${ }^{6}$.

Por lo menos 2 grupos reclaman haber sido los primeros en efectuar la colecistectomía por laparoscopía, uno en A lemania y el otro en Francia. Lo cierto es que a finales de los 80 este abordaje se practicaba ya en varios países del orbe $^{2}$, ya que brindaba grandes ventajas a los pacientes, en cuanto a dolor e incapacidad. Pero las trabas continuaban siendo lo costoso de los equipos y la necesidad de entrenar a los cirujanos en su uso para brindar absoluta seguridad a los pacientes y lograr estándares de calidad similares a los de la colecistectomía abierta.

La llegada y amplia aceptación de esta técnica, aunada a otros métodos como la papilotomía por endoscopía han cambiado el manejo habitual de los pacientes con enfermedad del tracto biliar. A nteriormente era frecuente la "colecistectomía abierta con exploración de vías biliares", sobre todo en casos agudos, procedimiento difícil y no exento de complicaciones aún en las mejores manos. Hoy en día se prefiere facilitar la expulsión o remoción de los cálculos endoscópicamente y luego "enfriar" el proceso para venir a posteriori a quitar la vesícula por laparoscopía. Con todo y eso la colecistectomía laparoscópica también puede hacerse en la colecistitis aguda con buenos resultados, dependiendo de la experiencia del cirujano ?

En nuestro medio los cirujanos haciendo un gran esfuerzo se prepararon independientemente y luego adquirieron los equipos necesarios para poner al alcance de sus pacientes privados este método de abordaje, habiendo actualmente 
grupos quirúrgicos con una casuística enorme. Posteriormente la Caja Costarricense de Seguro Social proveyó a algunos de sus Hospital es con esta tecnología para el bien de sus usuarios.

En esta edición de Acta Médica, Zúñiga y Vargas nos muestran la experiencia en cirugía de la vesícula abordada laparoscópicamente en el Hospital San Juan de Dios durante casi 3 años y comparan sus resultados con los de la colecistectomía abierta o clásica realizada durante el mismo periodo.

Los autores demuestran las bondades de este abordaje en su Institución, en un número considerable de enfermos, en comparación con la manera tradicional. Se debe de reconocer su esfuerzo, en la eterna búsqueda de mejores y menos cruentos métodos de tratamiento en la preparación constante del hombre al servicio del hombre.

El otro aspecto fundamental que este trabajo demuestra es la cautela que el Hospital San Juan de Dios ha exhibido en la implementación de los métodos de laparoscopía terapéutica, y que obviamente repite lo que ha ocurrido ya en todos los hospitales del mundo y del país cuando estas técnicas se empiezan a utilizar.

El Colegio Americano de Cirujanos ha dedicado muchas horas de trabajo al estudio del impacto de las nuevas tecnologías no sólo en los pacientes quienes las reciben, sino en el entrenamiento de los jóvenes residentes que aún sin terminar de aprender los métodos tradicionales deben empezar a exponerse y a dominar otros abordajes talvez no más difíciles, pero sí menos conocidos, aún a veces, por sus propios profesores ${ }^{8}$. ¿Cómo y cuándo van a aprender a realizar estos procedimientos ?,¿Será en animales ? ¿Cuántos deberán de ver antes de intentar hacer uno ?, etc.
Finalmente, si algún profesional ha debido de mantener la concentración, ese ha sido el cirujano. Con la llegada de la laparoscopía en que puede haber complicaciones inherentes al uso de un instrumental más agudo y alargado, uso de fuentes de energía calórica y coordinación del ojo y la mano y en ocasiones el pie simultáneamente, la concentración es no solo un requerimiento sino una virtud.

\section{Referencias}

1. Dacosta JC. Diseases and injuries of the abdomen, en M odern Surgery. Philadel phia. W B. Saunders, 1918, p:1123-1131.

2. Macintyre IMC., Wilson RG. La colecistectomía laparoscópica. Br J Surg (Ed. Esp.) 1993; 80:552-559.

3. M CSherry CK. Cholecistectomy: the gold standard. Am J Surg 1989; 158:174-178.

4. Morgenstern L., Wong L., Berci G. Twelve hundred open cholecystectomies in the prelaparoscopic era: a standard for comparison. A rch Surg 1992; 127: 400-403.

5. Stellato TA. History of laparoscopic surgery. Surg Clin N A. 1992; 72:997-1002.

6. Alvarado EM ., Hofman C., Salazar C. Video-Toracoscopía. Revista M édica de Costa Rica y Centro-A mérica. 1999; 56:155-160.

7. Ferzli G., Kloss DA. Laparoscopic cholecystectomy in both chronic and acute cholecystitis. Contemporary Surgery. 1992; 40:17-19.

8. Rhodes RS. N ew technology and new approaches to surgical education. Bulletin A merican College of Surgeons. 2001; 86: 16-17.

\author{
CarlosSalazar-Vargas \\ FACS. FCCP.FAHA \\ Hospital Calderón Guardia
}

